10. Weinreb I, Shaw AJ, Perez-Ordoñez B, Goldblum JR, Rubin BP. Nodular fasciitis of the head and neck region: a clinicopathologic description in a series of 30 cases. J Cutan Pathol. 2009;36:1168-73.
11. Grabam B, Barret T, Goltz R. Nodular fasciitis: response to intralesional corticosteroids. J Am Acad Dermatol. 1990;40:490-2.

12. Majumdar B. Spontaneously regressing nodular fasciitis of the neck. J Laringol Otol. 1983;97:973-7.

doi:10.1016/j.maxilo.2011.06.002

\title{
Tumor de Abrikossoff
}

\section{Abrikossoff tumor}

\section{Mireia Melero Luque ${ }^{a, *}$, Carlos D Arranz-Obispo ${ }^{a}$ y Antonio Monner-Diéguez ${ }^{a}$ August Vidal-Bel ${ }^{b}$}

a Servicio de Cirugía Oral y Maxilofacial, Hospital Universitario de Bellvitge, L’Hospitalet de Llobregat, Barcelona, España

b Servicio de Anatomía Patológica, Hospital Universitario de Bellvitge, L’Hospitalet de Llobregat, Barcelona, España

\section{Discusión}

El diagnóstico anatomopatológico definitivo fue de tumor de células granulares con márgenes libres (fig. 1). El paciente no presenta recidiva de la lesión después de un año y sigue controles habituales en consultas externas.

El tumor de células granulares (TCG) fue descrito por primera vez en 1926 por Alexei Ivanovich Abrikossoff. Otros nombres que ha recibido desde su descripción son mioblastoma, tumor de Abrikossoff, schwannoma de células granulares,... Se trata de una neoplasia infrecuente, benigna en la mayoría de caso, que afecta a tejidos blandos, piel y mucosas.

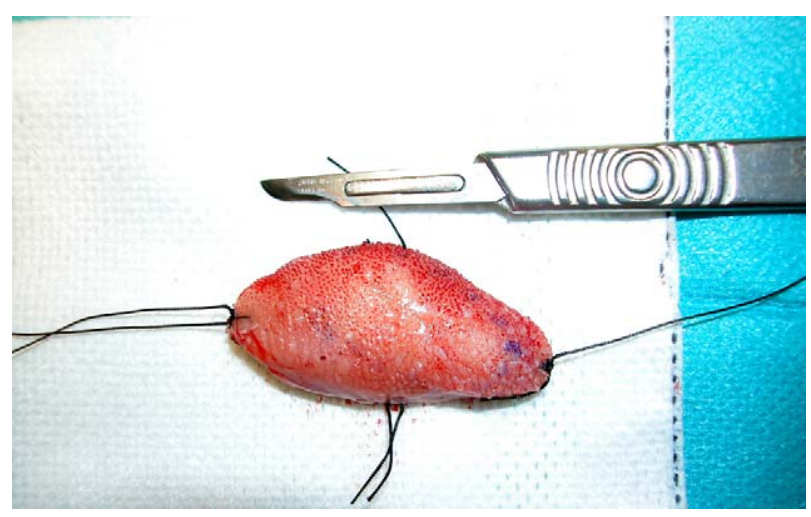

Figura 1 - Imagen macroscópica de la pieza quirúrgica.
El TCG puede aparecer a cualquier edad, con un rango de 20 a 60 años según la literatura. Se ha observado por parte de algunos autores una mayor prevalencia en mujeres y en raza negra.

Se localiza en cabeza y cuello entre un $45-60 \%$, siendo un $70 \%$ lesiones intraorales, pero pueden aparecer en cualquier zona del cuerpo ${ }^{1-3}$.

\section{Etiopatogenia y etiología}

La histogénesis del TCG sigue siendo un tema controvertido. Inicialmente, Abrikossoff atribuyó a las células mioblásticas estaminales su origen. Actualmente la mayoría de autores consideran a las células de Schwann las precursoras de este tumor. Esto se debe a los estudios inmunohistoquímicos en que se observa positividad a proteína S-100, vicentina y glicoproteínas NKI/C3. Otro hecho a su favor es la observación mediante microscopio electrónico de una membrana basal continua pericelular que recuerda al perineuro y la presencia de estructuras compatibles con mielina en los liposomas. A pesar de ello permanecen aspectos no resueltos como el mecanismo en que estas células inician la diferenciación tumoral ${ }^{4-5}$.

La etiología del TCG también es desconocida. En 1980 Lack et al atribuyen la alta incidencia de TCG en la cavidad oral por el traumatismo crónico de los dientes y/o prótesis sobre la mucosa. Otros autores creen por el contrario que las hormonas sexuales median en el desarrollo tumoral ${ }^{6-7}$.

Véase contenido relacionado en DOI:

10.1016/j.maxilo.2011.05.005.

* Autor para correspondencia.

Correo electrónico: mmelero@bellvitgehospital.cat (M. Melero Luque). 


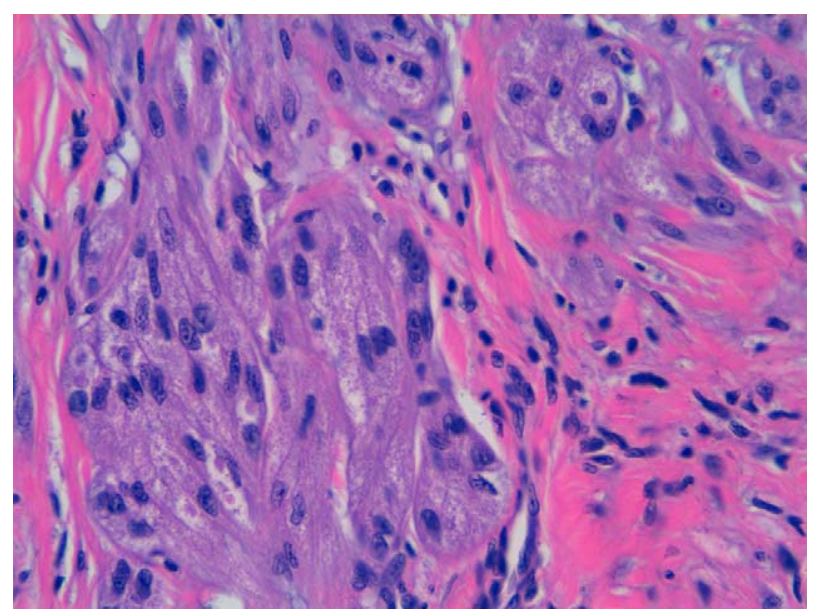

Figura 2 - Visión microscópica de la lesión en que se observan las células con citoplasma granular y nucleo redondeado típicas de este tumor (H-E 65x).

\section{Diagnóstico y diagnóstico diferencial}

El diagnóstico preoperatorio del TCG se basa en la historia clínica, exploración física, técnicas de imagen y biopsia incisional. Clínicamente son lesiones asintomáticas de crecimiento lento, bien definidas submucosas, y en el 75\% de los casos son lesiones únicas. Las pruebas de imagen como en TC nos permiten un estudio adecuado de su extensión pero no poseen certeza diagnóstica. El diagnostico de certeza se realiza con la biopsia incisional en la que se observan típicamente células poligonales con citoplasma eosinofílico granular y núcleo redondeado y pequeño. Las mitosis son un hallazgo excepcional (fig. 2). En ocasiones se puede observar una hiperplasia pseudoepiteliomatosa sobre el epitelio escamoso adyacente. La PAAF suele ser insuficiente para el diagnóstico ${ }^{8}$.

El TCG presenta normalmente un comportamiento benigno. Solo un $2 \%$ son malignos. Los criterios para diferenciarlos son: criterios clínicos (dolor, crecimiento rápido, ulceración, $>4 \mathrm{~cm}, .$. .) y criterios histológicos descritos por Fanburg and Smith en 1998 (necrosis, distribución fusiforme de las células, aumento del núcleo con vesículas, aumento del índice mitótico, aumento del radio del núcleo en relación con el citoplasma, pleomorfismo nuclear) ${ }^{9}$.

El diagnóstico diferencial se debe hacer con otras neoplasia conectivas y neurales benignas como el fibroma, lipoma, neurofibroma, schwannomas, neuromas. Y en el caso de las formas malignas con otros carcinomas.

\section{Tratamiento y pronóstico}

El tratamiento del TCG es exclusivamente quirúrgico, realizando la exéresis completa de la lesión. Si se sospecha malignidad debe incluirse la disección ganglionar ${ }^{10}$.
La exéresis incompleta de la lesión conlleva una tasa de recidiva elevada del 15\%, mientras que si la resección es correcta desciende al 1-3\%.

El uso de quimioterapia y/o radioterapia como tratamientos adyuvantes debe contemplarse en el caso de TCG malignizados.

\section{Reconocimientos}

El caso clínico fue presentado como póster en el XX EACMFS Congress de Brujas 2010.

\section{Conflicto de intereses}

Los autores declaran no tener ningún conflicto de intereses.

\section{B I B L I O G R A F Í A}

1. Bomfin LE, Alves A, De Almeida OP, Kowalski LP, Pérez DE. Multiple granular cell tumors of the tongue and parotid gland. Oral Surg Oral Med Oral Pathol Oral Radiol Endod. 2009 May;107:e10-3.

2. López-Jornet P. Granular cell tumor of the tongue. N Y State Dent J. 2008 Aug-Sep;74:71-2.

3. Giuliani M, Lajolo C, Pagnoni M, Boari A, Zannoni GF. Granular cell tumor of the tongue (Abrikossoff's tumor). A case report and review of the literature. Minerva Stomatol. 2004 Jul-Aug;53:465-9.

4. Vered M, Carpenter WM, Buchner A. Granular cell tumor of the oral cavity: updated immunohistochemical profile. J Oral Pathol Med. 2009 Jan;38:150-9.

5. Ordoñez NG, Mackay B. Granular cell tumor: a review of the pathology and histogenesis. Ultrastruct Pathol. 1999 Jul-Aug;23:207-22.

6. Becelli R, Perugini M, Gasparini G, Cassoni A, Fabiani F. Abrikossoff's tumor. J Craniofac Surg. 2001 Jan;12:78-81.

7. Eguia A, Uribarri A, Gay Escoda C, Crovetto MA, Martínez-conde R, Aguirre JM. Granular cell tumor: report of 8 intraoral cases. Med Oral Patol Oral Cir Bucal. 2006;11:E425-8.

8. Fitzhugh VA, Maniar KP, Gurudutt VV, Rivera M, Chen H, Wu M. Fine-needle aspiration biopsy of granular cell tumor of the tongue: a technique for the aspiration of oral lesions. Diagn Cytopathol. 2009 Nov;37:839-42.

9. Vered M, Carpenter WM, Buchner A. Granular cell tumor of the oral cavity: updated inmunohistochemical profile. J Oral Pathol Med. 2009;38:150-9.

10. Angiero F, Crippa R, Stefani M. Granular cells tumour in the oral cavity: report of eleven cases treated with laser surgery. Minerva Stomatol. 2006 Jul-Aug;55:423-30.

doi:10.1016/j.maxilo.2011.06.003 